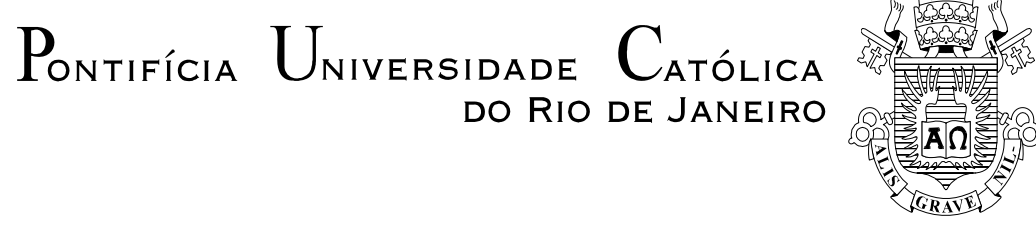

Elen Nogueira Lima Coutinho

As Variâncias do Corpo: Uma leitura psicanalítica
sobre as modificações corporais

Dissertação de Mestrado

Dissertação apresentada como requisito parcial para obtenção do grau de Mestre pelo Programa de Pósgraduação em Psicologia do Departamento de Psicologia da PUC-Rio.

Orientadora: Prof. Monah Winograd

Rio de Janeiro

Setembro de 2011 


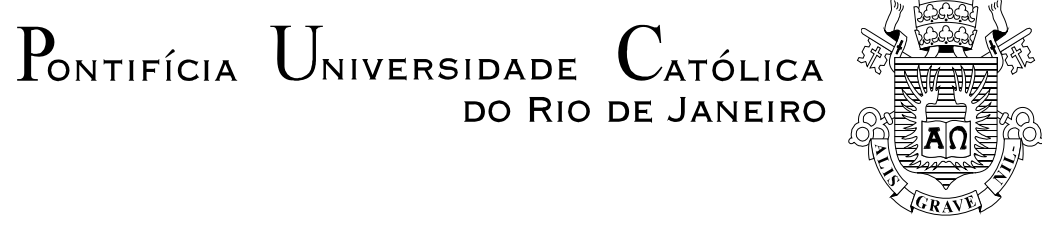

Elen Nogueira Lima Coutinho

\section{As Variâncias do Corpo: Uma leitura psicanalítica sobre as modificações corporais}

Dissertação apresentada como requisito parcial para obtenção do grau de Mestre pelo Programa de PósGraduação em Psicologia Clínica do Departamento de Psicologia do Centro de Teologia e Ciências Humanas da PUC-Rio. Aprovada pela Comissão Examinadora abaixo assinada.

Profa. Monah Winograd

Orientadora

Departamento de Psicologia - PUC-Rio

Profa. Flavia Sollero de Campos Departamento de Psicologia - PUC - Rio

Profa. Simone Perelson Departamento Psicologia - UFRJ

Profa. Denise Berruezo Portinari Coordenadora Setorial de Pós-Graduação

e Pesquisa do Centro de Teologia e Ciências Humanas - PUC-Rio

Rio de Janeiro, 30 de setembro de 2011. 
Todos os direitos reservados. É proibida a reprodução total ou parcial do trabalho sem autorização da universidade, da autora e da orientadora.

\section{Elen Nogueira Lima Coutinho}

Graduou-se em Psicologia pela Faculdade Salesiana de Filosofia; Ciências e Letras de Lorena em 1991; pós-graduação em Psicologia Clínica pela PUC-RJ ; pós-graduação pela Santa Casa de Misericórdia do RJ em Saúde Mental na Infância e Adolescência. Trabalhou na área de Psicologia Clínica com remuneração desde o início de sua carreira profissional, exercendo a função de psicoterapeuta. Atualmente, desde 2008, trabalha também como professora no Curso de Especialização em Transtornos Alimentares da CCEPUC-Rio.

Ficha Catalográfica

Coutinho, Elen Nogueira Lima

As variâncias do corpo: uma leitura psicanalítica sobre as modificações corporais / Elen Nogueira Lima Coutinho ; orientadora: Monah Winograd. - 2011.

126 f. ; $30 \mathrm{~cm}$

Dissertação (mestrado) - Pontifícia Universidade Católica do Rio de Janeiro, Departamento de Psicologia, 2011.

Inclui bibliografia

1. Psicologia - Teses. 2. Corpo. 3. Modificações corporais. 4. Manipulações corporais. 5. Eu. 6. Pele. I. Winograd, Monah. II. Pontifícia Universidade Católica do Rio de Janeiro. Departamento de Psicologia. III. Título. 
Para Adailto e Marlene, pela vida e pelo amor.

Para Péricles, pelo amor e companheirismo.

Para Eduardo e Victor, pelo amor e pela nobreza da maternidade. 


\section{Agradecimentos}

À Monah Winograd, pelo privilégio do feliz encontro entre uma aprendiz e sua orientadora que exerce a função com a sabedoria e a maestria que somente os que são conhecedores da "alma” possuem.

À CAPES e à PUC-Rio, pelos auxílios concedidos, sem os quais este trabalho não poderia ser realizado.

Ao dr. Maurício Magalhães Costa por ter salvo minha vida.

À minha família, rico berço de meus nascimentos biológico e psíquico.

Ao meu marido, pelo amor e companheirismo sempre presentes.

Aos meus filhos pela compreensão e carinho.

Aos colegas de mestrado e seus inquietantes e férteis pensamentos e articulações nas reuniões das quartas-feiras.

Joana Camelier, carinho é remédio, meus agradecimentos.

Dirce Freire, cuidado é também cura, sem palavras para agradecer.

Aos professores da banca examinadora. 


\section{Resumo}

Coutinho, Elen Nogueira Lima; Winograd, Monah (Orientadora). As Variâncias do Corpo: Uma Leitura Psicanalítica sobre as Modificações Corporais. Rio de Janeiro, 2011, 126p. Dissertação de Mestrado - Departamento de Psicologia, Pontifícia Universidade Católica do Rio de Janeiro.

O presente trabalho abordará as modificações corporais especificamente no campo psicanalítico. Partirá da premissa de que a questão da noção do corpo na psicanálise é fundamental e delicada, ressaltará a importância da via sensorial para a constituição do psiquismo. A investigação terá como base teórica o conceito freudiano de eu, a proposta de Piera Aulagnier a respeito da constituição do corpo próprio e da origem do psiquismo, as noções de Eu-pele e Eu-pensante de Didier Anzieu, alguns conceitos winnicottianos sobre a importância do vínculo materno na díade mãe-bebê para promoção de saúde mental, bem como algumas noções sobre saúde e criatividade. O trabalho visa refletir sobre as possíveis relações existentes entre as modificações corporais e a constituição da subjetividade.

\section{Palavras-chave}

Corpo; modificações corporais; manipulações corporais; eu; pele. 


\section{Abstract}

Coutinho, Elen Nogueira Lima; Winograd, Monah (Advisor). The Variances of the Body: A Psychoanalytic Reading on Body Modifications. Rio de Janeiro, 2011, 126p. MSc Dissertation Departamento de Psicologia, Pontifícia Universidade Católica do Rio de Janeiro.

The present work will address the body modifications specifically in the psychoanalytic field. It assumes the question of the notion of the body in psychoanalysis as a fundamental and delicate one, will underscore the importance of the sensorial pathway for the constitution of the psyche. The investigation will have as its theoretical basis the Freudian concept of ego, Piera Aulagnier's proposal regarding the constitution of one's own body and the psyche's origin, the notions of self-skin and self-thinking of Didier Anzieu, some Winnicottian concepts about the importance of maternal bond in the mother-infant dyad towards the promotion of mental health, as well as some notions of health and creativity. The work intends to consider the possible relations between body modifications and the constitution of subjectivity.

\section{Keywords}

Body; body modifications; body manipulations; ego; skin. 


\section{Sumário}

Introdução

10

$\begin{array}{ll}\text { Sobre as Modificações Corporais } & 20\end{array}$

1. Um Lugar de Inscrição $\quad 30$

1.1 - Os Corpos do Corpo Freudiano 31

1.2 - O Corpo como Lugar 39

1.3 - O Nascimento de um Corpo 43

1.4 - Origem de uma História 52

2. Sobre a Pele e o Psiquismo 65

2.1 - A Pele, uma Zona Erógena 67

2.2 - A Função Primária da Pele $\quad 76$

2.3 - Do Eu-Pele ao Eu Freudiano 89

3. As Variâncias do Corpo $\quad 97$

3.1 - As Técnicas do Corpo 98

3.2 - O Agir Expressivo 105

3.3 - A Saúde Modificada 110

$\begin{array}{lr}\text { 4. Conclusão } & 118\end{array}$

5. Referências bibliográficas 122 
A única coisa talvez que eu lhes pediria que guardassem de tudo que defendi esta noite diante de vocês, é a idéia da estrutura psíquica desdobrada como formação intermediária no diálogo entre o corpo e o mundo. Por que? Porque esse diálogo é brutal, porque a luz do mundo é ofuscante, porque as exigências do corpo são tirânicas, e se não dispuséssemos dessa formação amortecedora dos choques, que é constituída pelo psiquismo inconsciente e pelo psiquismo consciente, estaríamos ainda, provavelmente, num estádio préhominiano. Obrigado. ${ }^{1}$

André Green, 1986

\footnotetext{
${ }^{1}$ Nesta pesquisa nas citações diretas e títulos de obras (livros e artigos), a ortografia antiga será mantida, por fidelidade à obra citada.
} 